\title{
The Rotter level of aspiration task: A validity study
}

Rohe N. Eshbaugh and Stanley R. Friedman UNIVERSITY OF LOUISVLLE

\begin{abstract}
Thirty-six subjects were classified as cautious (C) or non-cautious (NC) on the Rotter Level of Aspiration Task. It was hypothesized that subjects classified as $\mathrm{C}$ would produce larger difference limens (DLs) than NC subjects on an auditory discrimination task using the Method of Constant Stimuli. The hypothesis was confirmed. The two techniques were compared as behavioral measurement instruments.
\end{abstract}

\section{Introduction}

In recent years there has been an increasing interest in studies of risk-taking behavior. The basic assumption has been that individuals can be classified as to their strategies in a choice situation. Two of the classifications are risk-takers and non-risk-takers. A risk-taker is an individual who is willing to risk loss in order to maximize gain, while a non-risk-taker chooses as if to minimize loss. Quite often these two classes are referred to as cautious (non-risk-takers) and non-cautious (risk-takers) individuals.

J. B. Rotter (1945) has developed a "level of aspiration" task which he claims, on the basis of his investigations, can distinguish persons who exhibit cautious (C) patterns of behavior from those who show non-cautious (NC) behavior. The task is described by Rotter and consists of having a subject predict his future performance, on a task almost completely independent of skill, on the basis of his past performance. Various patterns of prediction are taken to be indicative of $\mathrm{C}$ or $\mathrm{NC}$ behavior: a pattern may be also non-classifiable. Behavior in the situation-how subjects shift their goals after success and failure, how high their goals are, and how often they shift their estimation-determines whether they will be classified as $\mathrm{C}, \mathrm{NC}$, or non-classifiable individuals.

Woodworth \& Schlosberg (1954, p. 215) discuss C and NC behavior in the context of psychophysical judgments and point out that the difference limen (DL) of the Method of Constant Stimuli (MCS) "measures something different from accuracy of judgment. It measures directly O's inclination to use the middle category, and indirectly the complex of factors responsible for this inclination. ...the IU of Constant Stimuli is a measure of attitude rather than discrimination." They point out that a highly confident individual (p. 213) "may plunge for the plus and minus responses and avoid 'equal' as a sign of indecision or overcarefulness." In contrast, a "cautious person... will not give a plus or minus response unless he is perfectly sure."

Fernberger (1931) demonstrated that subjects' attitudes can be changed by varying instructions in a psychophysical task using the MCS. The change in attitude shows up in the size of the DL. The DL was smaller for instructions designed to make $\mathrm{S}$ commit himself, and risk error, while instructions which allowed the subject to be $\mathrm{C}$ and report "equal" or "uncertain" resulted more frequently in a larger DL.

The present experiment is designed to test the hypothesis that subjects producing $C$ patterns on the Rotter Level of Aspiration Task will have larger DLs in an auditory discrimination task than subjects producing NC patterns. We assume that if a $\mathrm{C}$ person behaves consistently, his performance on the Rotter task should result in a $C$ pattern of behavior coupled with a larger DL from the MCS. The individual who is willing to risk error, on the other hand, will have a pattern of NC behavior on the Rotter task and a smaller DL on the psychophysical task.

\section{Apparatus}

The Level of Aspiration Task has been previously described in the literature (Rotter, 1942).

For the auditory discrimination task, the output of a Grason-Stadler White Noise Generator was fed into a General Radio Decade Attenuator Type 1450, through a knife-switch, to a set of earphones.

\section{Subjeets}

Fifty-four subjects from introductory psychology classes at the University of Louisville were used. The subjects were members of classes where-in they are required to participate in at least four experiments. Eighteen subjects were classified as $\mathrm{C}$ and eighteen as $\mathrm{NC}$; the remaining subjects were non-classifiable. Procedure

Each subject was classified by one experimenter on the level of aspiration task, and then was taken to another room to be tested on the auditory discrimination task by another experimenter. The subject was seated on one side of a partition so as not to be able to view the apparatus or experimenter. The subjects auditory threshold (RL) was determined by the Method of Limits; for the MCS, the standard tone (St) was chosen to be $20 \mathrm{db}$ above this threshold. Nine comparison tones (Co) were used: one equal in intensity to the St and four above it and four below it in $1 \mathrm{db}$ increments. The St and Co pairs were presented in random order, each pair being presented a total of five times, with the St always being first. The subjects made their judgments verbally.

\section{Instructions}

"You will hear a series of pairs of sounds. Your job is to tell me whether, for each pair of sounds, you think the second sound is louder or softer than the first, or whether you are uncertain. The responses you may give me then are louder, softer, or uncertain with respect to the second sound of each pair. Any questions?"' 
Table 1. Distribution of DLs for C and NC Subjects

$\begin{array}{rrc} & \text { Small DL } & \text { Large DL } \\ \mathrm{C} & 5 & 13 \\ \mathrm{NC} & 12 & 6\end{array}$

$\mathrm{X}^{2}=5.46$

$\mathrm{p}<.02$

\section{Results}

DLs were calculated for each subject and were rankordered, after which the distribution was divided at the median. A 2 X 2 table (C-NC Xbelow median DL-above median DL) was made (Table 1) and a Median Test performed (Siegel, 1956).

The distribution was found to be significant at better than the .02 level of probability.

\section{Diseussion}

The results support our hypothesis. Subjects who show cautious predictive patterns on the Rotter instrument do tend to give larger DLs on an auditory discrimination task. The range of DLs was from $1.90 \mathrm{db}$ to $.60 \mathrm{db}-\mathrm{a}$ range of only $1.30 \mathrm{db}$. Since we are attempting to discriminate behavior on the basis of score within such a restricted range (using DL as the predictive criterion), it is immediately obvious that there is little room for error variance-a slight deviation from the subject's true score might place him in the "wrong" category. Thus, since we must use small incremental steps in selecting the series of Co (due to the sensitivity level of human auditory discrimination), we must work under the assumption that DL appears logically to meet this criterion, and beyond that we can only appeal to the confirmatory evidence of behavioral observation.
The Rotter instrument thus would appear to measure what it is purported to measure: $\mathrm{C}$ and NC behavior. However it appears that the measurement of DL in an auditory discrimination task gives us equivalent information without the disadvantage of eliminating non-classifiable patterns from consideration (non-classifiable subjects produced DLs distributed about evenly between the small DL and large DL groups)-there is no such thing as a non-classifiable DL!

Another important consideration is that the Rotter pattern classification system permits only a nominal scale, providing limitation of objective comparisons, since a subject can be only $\mathrm{C}$ or $\mathrm{NC}$ if he is classifiable. We can, however, form an ordinal scale of DLs (which in fact we did!) permitting the comparison of relative ranks of subjects. Comparisons of DL size may be made between individuals or groups of individuals and relative positions determined.

\section{Referenees}

FERNBERGER, S. W. Instructions and the psychophysical limen. Amer. J. Psychol., 1931, 43, 361-376.

ROTTER, J. B. Level of aspiration as a method of studying personality. J.exp. Psychol., 1942, 48, 463-474. ROTTER, J. B. Level of aspiration as a method of studying personality: IV, the analysis of patterns of response. J. soc. Psychol., 1945, 21, 159-177.

SIEGEL, S. Nonparametric statistics for the behavioral sciences. New York: McGraw-Hill, 1956.

WOODWORTH, R. S., \& SCHLOSBERG, H. Experimental psychology. (Rev. ed.) New York: Holt, Rinehart \& Wilson, 1954.

\section{Note}

1. The authors wish to acknowledge the comments and suggestions of Dr. E. A. Alluisi. 